\title{
Optical particle counter measurement of marine aerosol hygroscopic growth
}

\author{
J. R. Snider ${ }^{1}$ and M. D. Petters ${ }^{2}$ \\ ${ }^{1}$ Department of Atmospheric Science Dept. 3038, University of Wyoming, 1000 East University Avenue, Laramie, WY \\ 82071, USA \\ ${ }^{2}$ Department of Atmospheric Science 1371, Colorado State University, Campus Delivery Fort Collins, CO 80523-1371, USA
}

Received: 2 August 2007 - Published in Atmos. Chem. Phys. Discuss.: 22 August 2007

Revised: 20 December 2007 - Accepted: 13 February 2008 - Published: 4 April 2008

\begin{abstract}
A technique is developed for the determination of the hygroscopic growth factor of dry particles with diameter between 0.3 and $0.6 \mu \mathrm{m}$ and is applied to measurements made during the second Dynamics and Chemistry of Marine Stratocumulus experiment (DYCOMS-II). Two optical particle counters are utilized, one measures the aerosol size spectrum at ambient relative humidity and the other simultaneously dries the aerosol prior to light scattering detection. Growth factors are based on measurements made in the region of the Mie scattering curve where scattered light intensity increases monotonically with dry and wet particle diameter, i.e. $D<0.9 \mu \mathrm{m}$. Factors influencing the accuracy of the measurement are evaluated, including particle drying, refractive index and shape. Growth factors at $90 \pm 3 \%$ ambient relative humidity in marine airmasses $400 \mathrm{~km}$ west of San Diego, California range between 1.5 and 1.8. This suggests that a significant fraction of the particle mass, between 40 and $70 \%$, is either non-hygroscopic or weakly hygroscopic.
\end{abstract}

\section{Introduction}

The equilibrium size of an aerosol particle at a specified relative humidity, compared to its dry size, defines what is commonly called the hygroscopic growth factor $(G F)$. Accurate knowledge of the growth factor is important in studies of visibility (McMurry and Stolzenburg, 1989) and direct aerosol forcing of climate (Boucher and Anderson, 1995). Growth factors are also linked to cloud condensation nuclei activity (Svenningsson et al., 1994; Brechtel and Kreidenweis, 2000; Snider et al., 2003; Kreidenweis et al., 2005; Massling et al., 2005; Mertes et al., 2005; Rissler et al., 2006; Svenningsson

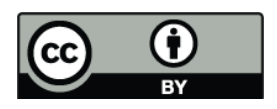

Correspondence to: J. R. Snider (jsnider@uwyo.edu) et al., 2006; Petters and Kreidenweis, 2007) and as such help to constrain the first indirect effect of aerosol on climate.

Growth factors vary with the relative amounts of hygroscopic and non-hygroscopic material carried by a particle, and with the degree to which a fixed amount of hygroscopic material lowers the water saturation vapor pressure above an aqueous solution. When a hydrated particle is exposed to decreasing relative humidity ( $\mathrm{RH})$ a solubility limit is approached and beyond this point the particle can exist as a solution in metastable equilibrium with its surroundings, or can effloresce (Tang and Munkelwitz, 1994). Atmospheric measurements made at $\mathrm{RH}$ values less than that characterizing deliquescence of common salts, but in excess of $\mathrm{RH}=45 \%$, show that the metastable particles are typical (Rood et al., 1989; Berg et al., 1998; Santarpia et al., 2004). Laboratory studies show that if the hydrated particle contains more than one solute, and in particular when organics are present, the value of RH required for efflorescence is lower than that for a particle composed of a single solute (Martin, 2000; Marcolli et al., 2004; Parsons et al., 2004).

Most measurements of the $G F$ have focused on particles with dry diameters smaller than $0.3 \mu \mathrm{m}$ diameter using a hygroscopic tandem differential mobility analyzer (HTDMA) (for a review see McFiggans et al., 2006). Fewer studies (Strapp et al., 1992; Hitzenberger et al., 1997; Kotchenruther and Hobbs, 1998; Wulfmeyer and Feingold, 2000; Feingold and Morley, 2003; Hegg et al., 2006; Turšič et al., 2006) have characterized the hygroscopic behavior of particles larger than $0.3 \mu \mathrm{m}$, using instruments other than an HTDMA. Here we advance a technique, briefly described by Kotchenruther and Hobbs (1998), for determining the hygroscopic response of aerosol particles having a dry diameter larger than $0.3 \mu \mathrm{m}$. The technique uses concurrent measurements of aerosol size spectra obtained from a model 300 forward scattering spectrometer probe (Baumgardner et al., 1992, hereafter F300) and a passive cavity aerosol spectrometer probe (Liu et al., 1992, hereafter PCASP). While the former detects particles

Published by Copernicus Publications on behalf of the European Geosciences Union. 
at ambient $\mathrm{RH}$, the latter dries particles to $\mathrm{RH}<40 \%$ (Strapp et al., 1992), thereby permitting retrieval of the hygroscopic growth factor.

We analyze PCASP and F300 measurements and derive the $G F$ of particles of dry diameter larger than that accessible with a conventional HTDMA. Results are presented for 31 constant-altitude circles flown within and above a summertime marine boundary layer. We report data from seven days during the time of peak stratocumulus cloud occurrence over the northeastern Pacific. Measurements conducted in dry air above the marine boundary layer $(\mathrm{RH} \leq 36 \%)$ were used to infer the sample flow rate through the F300 and to also establish that hygroscopic growth factors in this regime are close to unity. The latter result is expected since the ambient RH is too low to sustain water amounts on the F300-detected particles significantly in excess of that on the PCASP-detected particles. For measurements made within the boundary layer, where the ambient RH ranged between 71 to $96 \%$, we report $G F$ values which are somewhat smaller than that of laboratory generated sodium sulfate particles.

\section{Measurements}

\subsection{DYCOMS-II}

Field studies were conducted during seven research flights (RF01, RF02, RF03, RF04, RF05, RF07 and RF08) flown over the northeastern Pacific during the second Dynamics and Chemistry of Marine Stratocumulus experiment (DYCOMS-II; Stevens et al., 2003). The measurement platform used for the study was the C-130 aircraft operated by the National Center for Atmospheric Research with support from the National Science Foundation. Flights were conducted during July 2001 and the approximate location of the target area was $122^{\circ} \mathrm{W}$ and $31^{\circ} \mathrm{N}(400 \mathrm{~km}$ southwest of San Diego, CA). The time interval used to average the C-130 data was approximately $30 \mathrm{~min}$. This corresponds to sampling conducted along one of many $60 \mathrm{~km}$ (diameter) constantaltitude circles flown by the $\mathrm{C}-130$ above and below stratocumulus cloud layers during DYCOMS-II (Stevens et al., 2003). Hereafter, we refer to the $60 \mathrm{~km}$ circles as segments.

\subsection{Data selection}

We analyze C-130 data sampled once per second and archived in Network Common Data Format (NetCDF) by the National Center for Atmospheric Research. Three to five below-cloud segments, and one above-cloud segment, are available for each flight. Averaged values of $\mathrm{RH}$, derived from measured temperature and dew point (used throughout to quantify the humidity), range from 6 to $36 \%$ and from 71 to $96 \%$ during the above-cloud and below-cloud segments.

To avoid particles produced by the impact and shattering of drizzle impinging on the inlet of the PCASP (Weber et al., 1998; Guibert et al., 2003; Petters et al., 2006) we selected a drizzle-free subset of the below-cloud segments. The selection was performed using data from a wing-mounted two-dimensional optical array probe (2DC, vanZanten et al., 2005). Our criterion is that the current datum, and the seconds both preceding and following the current datum, is associated with drizzle concentrations less than 1 per liter. This criterion eliminates between 21 and 59\% of the size spectra from the three below-cloud segments of RF07 - the flight associated with the largest amount of drizzle (vanZanten et al., 2005). A consequence is that the count of PCASP particles per size bin for the largest diameter channel considered in Sect. 3.1 was as small as 115 for one of the RF07 below-cloud segments. For all of the other below-cloud segments (two other from RF07 and 24 total) this count was never smaller than 84 and was usually larger than 150 . In our plots of the segment-averaged size spectra we show the Poisson errors for each OPC channel. Calculation of the averaged spectral densities and their Poisson error is described in Sect. 2.4.

\subsection{Optical particle counter measurements}

Data from two wing-mounted optical particle counters (OPC) operated on the C-130 are utilized: the 1) PCASP, and 2) the F300. During DYCOMS-II these were mounted below the right wing and both used the signal-processing hardware and firmware developed by Droplet Measurement Technologies (Boulder, CO). These OPCs detect light scattered from particles crossing a helium-neon laser beam $(\lambda=0.633 \mu \mathrm{m})$; we refer to this process as a transit event.

The channel-to-diameter assignments shown in the first six columns of Table 1 assume an index of refraction of polystyrene latex (refractive index $n=1.59$ ) and are based on Mie scattering theory which assumes spherical particle shape. Also presented are assignments for the F300 when sampling pure water droplets $(n=1.33$, Baumgardner et al., 1992). The assignment for $n=1.59$ is validated by challenging the OPCs with aerosols composed of nearly monodisperse polystyrene latex spheres. While necessary for establishing the sizing accuracy, such exercises do not challenge the PCASP and F300 simultaneously, nor do they assess the accuracy of the PCASP and F300 concentration measurement. As we show in Sect. 3.2, the latter is possible by analyzing data from the above-cloud $(\mathrm{RH}<36 \%)$ flight segments.

The PCASP sizes particles by detecting light scattered into the angles 35 to $120^{\circ}$, measured from the forward direction (Liu et al., 1992; Strapp et al., 1992; Collins et al., 2000). The PCASP's three inlet heaters (Collins et al., 2000) are automatically activated when the C-130 leaves the runway. Because of adiabatic and diabatic warming of the sample occurring prior to a transit event, particles sampled from a humid boundary layer are detected at an RH estimated to be no larger than 40\% (Strapp et al., 1992). Mixing of the sample 
Table 1. Channel-to-diameter assignments.

\begin{tabular}{|c|c|c|c|c|c|c|c|c|}
\hline \multicolumn{3}{|c|}{$\begin{array}{c}\text { PCASP } \\
\text { Above- and Below-cloud }^{\mathrm{c}}\end{array}$} & \multicolumn{3}{|c|}{$\begin{array}{c}\text { F300 } \\
\text { Above-cloud }^{\mathrm{c}, \mathrm{d}}\end{array}$} & \multicolumn{3}{|c|}{$\begin{array}{c}\text { F300 } \\
\text { Below-cloud }^{\mathrm{c}, \mathrm{e}}\end{array}$} \\
\hline Channel & Lower & Upper & Channel & Lower & Upper & Channel & Lower & Upper \\
\hline 0 & 0.09 & 0.10 & 0 & 0.30 & 0.35 & 0 & 0.38 & 0.43 \\
\hline 1 & 0.10 & 0.11 & 1 & 0.35 & 0.40 & 1 & 0.43 & 0.48 \\
\hline 2 & 0.11 & 0.12 & $2^{a}$ & 0.40 & 0.45 & 2 & 0.48 & 0.52 \\
\hline 3 & 0.12 & 0.13 & $3^{a}$ & 0.45 & 0.50 & 3 & 0.52 & 0.57 \\
\hline 4 & 0.13 & 0.14 & $4^{\mathrm{a}}$ & 0.50 & 0.55 & $4^{b}$ & 0.57 & 0.61 \\
\hline 5 & 0.14 & 0.15 & $5^{\mathrm{a}}$ & 0.55 & 0.60 & $5^{b}$ & 0.61 & 0.65 \\
\hline 6 & 0.15 & 0.16 & $6^{\mathrm{a}}$ & 0.60 & 0.65 & $6^{b}$ & 0.65 & 0.70 \\
\hline 7 & 0.16 & 0.17 & $7^{a}$ & 0.65 & 0.70 & $7^{b}$ & 0.70 & 0.84 \\
\hline 8 & 0.17 & 0.18 & $8^{a}$ & 0.70 & 0.80 & 8 & 0.84 & 0.89 \\
\hline 9 & 0.18 & 0.20 & 9 & 0.80 & 0.90 & 9 & 0.89 & 0.93 \\
\hline 10 & 0.20 & 0.22 & 10 & 0.90 & 1.00 & 10 & 0.93 & 0.96 \\
\hline 11 & 0.22 & 0.24 & 11 & 1.00 & 1.20 & 11 & 0.96 & 1.05 \\
\hline 12 & 0.24 & 0.26 & 12 & 1.20 & 1.40 & 12 & 1.05 & 1.12 \\
\hline 13 & 0.26 & 0.28 & 13 & 1.40 & 1.70 & 13 to 15 & 1.12 & 2.63 \\
\hline 14 & 0.28 & 0.30 & 14 & 1.70 & 2.00 & 16 & 2.63 & 2.73 \\
\hline $15^{b}$ & 0.30 & 0.40 & 15 & 2.00 & 2.50 & 17 to 20 & 2.73 & 4.94 \\
\hline $16^{\mathrm{a}, \mathrm{b}}$ & 0.40 & 0.50 & 16 & 2.50 & 3.00 & 21 to 22 & 4.94 & 7.08 \\
\hline $17^{\mathrm{a}, \mathrm{b}}$ & 0.50 & 0.60 & 17 & 3.00 & 3.50 & 23 to 24 & 7.08 & 10.04 \\
\hline $18^{\mathrm{a}}$ & 0.60 & 0.70 & 18 & 3.50 & 4.00 & 25 & 10.04 & 11.07 \\
\hline $19^{\mathrm{a}}$ & 0.70 & 0.80 & 19 & 4.00 & 4.50 & 26 & 11.07 & 11.35 \\
\hline 20 & 0.80 & 0.90 & 20 & 4.50 & 5.00 & 27 & 11.35 & 13.57 \\
\hline 21 & 0.90 & 1.00 & 21 & 5.00 & 6.00 & 28 to 29 & 13.57 & 21.41 \\
\hline 22 & 1.00 & 1.20 & 22 & 6.00 & 7.00 & & & \\
\hline 23 & 1.20 & 1.40 & 23 & 7.00 & 8.00 & & & \\
\hline 24 & 1.40 & 1.60 & 24 & 8.00 & 9.00 & & & \\
\hline 25 & 1.60 & 1.80 & 25 & 9.00 & 10.00 & & & \\
\hline 26 & 1.80 & 2.00 & 26 & 10.00 & 12.00 & & & \\
\hline 27 & 2.00 & 2.30 & 27 & 12.00 & 14.00 & & & \\
\hline 28 & 2.30 & 2.60 & 28 & 14.00 & 17.00 & & & \\
\hline 29 & 2.60 & 3.00 & 29 & 17.00 & 20.00 & & & \\
\hline
\end{tabular}

a Channels used for analyzing above-cloud PCASP and F300 data.

${ }^{b}$ Channels used for analyzing below-cloud PCASP and F300 data.

c Particle count rate measurements were extracted from the two-dimensional NetCDF arrays AS200_RPO and AS300_RPC, respectively. The array length is equal to the number of seconds in the flight and the array width is 31 . The first-width elements contain particle count rates equal to zero, for all times. This data was discarded and it not included in the channel numbering shown here.

d Sizing corresponding to $n=1.59$ (Baumgardner et al., 1992).

e F300 sizing corresponding to pure water ( $n=1.33$, Baumgardner et al., 1992).

and sheath air streams may also contribute to particle drying. The PCASP concentrations we report were derived as a ratio of particle count rate (number of particles per channel per second) and sample flow rate (actual cubic centimeter per second). Since the latter was measured (and archived) as a volumetric rate at standard pressure and temperature we convert to the actual flow rate using C-130 measurements of ambient pressure, $\mathrm{C}-130$ measurements of temperature plus $10^{\circ} \mathrm{C}$ (to account for the warming that occurs in the PCASP), and the standard state values $\mathrm{P}_{o}=1013 \mathrm{hPa}$ and $\mathrm{T}_{o}=293 \mathrm{~K}$. Typical values of the actual sample flow rate are $1 \mathrm{~cm}^{3} / \mathrm{s}$.
The F300 sizes particles by detecting light scattered into the angles 4 to $12^{\circ}$, measured from the forward direction (Baumgardner et al., 1992). Since the F300 samples particles unobtrusively, it can be used in conjunction with a dry particle size measurement to assess the growth factor. We define the F300 sample flow rate as product of the C-130 airspeed and the F300 sample area. Analogous to how we process the PCASP data, we divide the F300 sample flow rate into the particle count rate to obtain the concentration. Baumgardner et al. (1992) estimate the F300 sample area to be between 0.04 and $0.05 \mathrm{~mm}^{2}$, and in recognition of this 


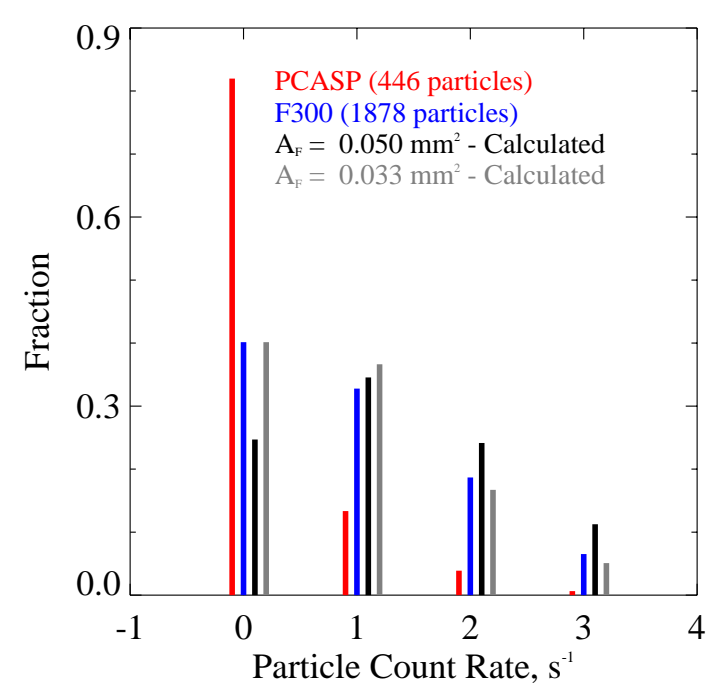

Fig. 1. Particle count rate distributions for the above-cloud segment on 10 July 2001 (RF01, 11:44 to 12:15 UTC). Particles classified between 0.4 and $0.8 \mu \mathrm{m}$ diameter were used to construct the empirically-based PCASP and F300 distributions, shown in red and blue, respectively. The segment-averaged PCASP count rate, two values of the F300 sample area and the Poisson distribution function (Young, 1962) were used to calculate the distributions shown in black and gray.

uncertainty, we developed a new method for inferring the sample area. We base our sample area estimate on particle count rate distributions formed by pooling measurements of particles classified between 0.4 and $0.8 \mu \mathrm{m}$ acquired during the seven above-cloud flight segments $(\mathrm{RH}<36 \%)$. As is evident from Table 1, this range of particle diameters is obtained from channels 2 to 8 and channels 16 to 19 of the F300 and PCASP, respectively. The analysis is premised on the assumption that particle count rate and concentration values reported by the PCASP are unbiased.

The particle count rate distribution, corresponding to the above-cloud segment of RF01, is shown for both OPCs in Fig. 1 (red and blue). We emphasize that these two distributions are constructed by pooling particle count rate measurements archived in the NetCDF file (Sect. 2.2). In contrast to such empirically-based count rate distributions, a distribution was calculated on the assumption that particle counting by F300 can be described by the Poisson distribution function (Young, 1962). A parameter used in that calculation is the segment-averaged F300 count rate $\left(\left\langle\dot{C}_{F}\right\rangle\right)$ which we derived as

$\left\langle\dot{C}_{F}\right\rangle=\frac{\left\langle\dot{C}_{P}\right\rangle \cdot\langle U\rangle \cdot A_{F}}{\left\langle\dot{V}_{P}\right\rangle}$.

Here $\left\langle\dot{C}_{P}\right\rangle$ is the segment-averaged PCASP count rate $(0.4<\mathrm{D}<0.8 \mu \mathrm{m}),\langle U\rangle$ is the segment-averaged airspeed of the C-130, $\left\langle\dot{V}_{P}\right\rangle$ is the segment-averaged PCASP sample flow rate (Sect. 2.3) and $A_{F}$ is the largest of two F300 sample ar- eas reported by Baumgardner et al. (1992) $\left(0.05 \mathrm{~mm}^{2}\right)$. The fraction of seconds with a specified number of counted particles $(N)$ was formulated according to the Poisson distribution function as

$$
f(N)=\frac{\left\langle\dot{C}_{F}\right\rangle^{N} \cdot \exp \left(-\left\langle\dot{C}_{F}\right\rangle\right)}{N !} .
$$

We show the prediction of Eq. (2), assuming $A_{F}=0.05 \mathrm{~mm}^{2}$, as a black histogram in Fig. 1 where it is apparent that the predicted distribution peaks at 1 particle per second while the empirical F300 distribution peaks at zero particles per second. A corrected F300 sample area was derived by adjusting $A_{F}$ in Eqs. (1) and (2) until the the Poisson distribution function agreed with the empirical F300 distribution at a count rate of zero particles per second. The result is shown (gray) and corresponds to $A_{F}=0.033 \mathrm{~mm}^{2}$. While the agreement at zero count rate is forced, the predicted particle count rates at one, two and three per second are also in reasonable agreement with the empirical F300 distribution. This calculation was repeated for the other six above-cloud segments. We use the average of this set, $\bar{x}=0.034 \pm 0.006 \mathrm{~mm}^{2}$ in our analysis. Assuming $A_{F}=0.034 \mathrm{~mm}^{2}$ and a representative airspeed for the C-130 $(U=110 \mathrm{~m} / \mathrm{s})$, the F300 sample flow rate is $3.7 \mathrm{~cm}^{3} / \mathrm{s}$, about a factor of four larger than that of the PCASP. Finally, we note that our result for the project-averaged F300 sample area differs only slightly from that obtained by forcing the above-cloud segment-averaged F300 concentration to be equal to the above-cloud segmentaveraged PCASP concentration. For the latter technique we obtain $\bar{x}=0.043 \pm 0.010 \mathrm{~mm}^{2}$.

\subsection{Spectra averaging and Poisson error}

Here we described how data extracted from the NetCDF files was used to evaluate the segment-averaged aerosol spectral densities and their Poisson error. For the i-th channel of the OPC, let $C_{i}$ represent the count of particles detected during either the above- or below-cloud sampling segments, and in the case of the latter, conditionally sampled with the belowcloud selection criterion (Sect. 2.2). The averaged spectral density was evaluated as

$$
\left\langle\frac{d N}{d \log _{10} D}\right\rangle_{i}=\frac{C_{i}}{V \cdot \log _{10}\left(D_{i} / D_{i-1}\right)}
$$

where $V$ is the sample volume for the selected portions of the flight segment (derived by summing measurements of the sample flow rate Sect. 2.3), and $D_{i-1}$ and $D_{i}$ are particle diameters defining the lower and upper limits of the channel (Table 1). The Poisson sampling error for this average is

$$
\sigma_{i}=\frac{\sqrt{C_{i}}}{V \cdot \log _{10}\left(D_{i} / D_{i-1}\right)} .
$$


Table 2. Model calculation of particle size and its response to a step change in RH.

\begin{tabular}{|c|c|c|c|c|c|c|}
\hline \multicolumn{7}{|l|}{ Initial Particle } \\
\hline $\begin{array}{l}\mathrm{RH} \\
\%^{\mathrm{a}}\end{array}$ & $\begin{array}{c}\text { Starting } \\
\text { equilibrium } \\
\text { wet diameter } \\
\mu \mathrm{m}^{\mathrm{b}}\end{array}$ & $\begin{array}{l}\text { Mass fraction } \\
\mathrm{Na}_{2} \mathrm{SO}_{4} \text { in } \\
\text { dry particle }\end{array}$ & $\begin{array}{l}\text { Non-hygroscopic } \\
\text { material density } \\
\mathrm{kg} / \mathrm{m}^{3}\end{array}$ & $\begin{array}{l}\text { Sphere equivalent } \\
\text { diameter of dry } \\
\text { particle }\end{array}$ & $\begin{array}{c}\mathrm{H}_{2} \mathrm{O} \text { vapor } \\
\text { accommodation } \\
\text { coefficient }\end{array}$ & $\begin{array}{c}\text { Refractive index } \\
\text { of solution } \\
\text { at } \mathrm{RH}=96 \%\end{array}$ \\
\hline 96 & 0.84 & 0.80 & 1200 & 0.387 & 0.003 & 1.36 \\
\hline \multicolumn{7}{|l|}{ Partially Dried Particle } \\
\hline $\begin{array}{l}\text { Wet diameter } \\
\text { after } 0.2 \mathrm{~s} \text { at } \mathrm{RH}=40 \% \\
\mu \mathrm{m}^{\mathrm{c}}\end{array}$ & $\begin{array}{c}\text { Metastable } \\
\text { diameter at } \\
\mathrm{RH}=40 \% \\
\mu \mathrm{m}^{\mathrm{c}}\end{array}$ & $\begin{array}{l}\text { Weight percent } \mathrm{H}_{2} \mathrm{O} \\
\text { in metastable solution } \\
\text { at } \mathrm{RH}=40 \%{ }^{\mathrm{c}}\end{array}$ & $\begin{array}{c}\text { Refractive index } \\
\text { of metastable } \\
\text { solution at } \mathrm{RH}=40 \% \mathrm{c}\end{array}$ & & & \\
\hline 0.48 & 0.48 & 36. & 1.41 & & & \\
\hline
\end{tabular}

${ }^{\text {a }}$ Largest segment-averaged ambient RH in this study (right panel of Fig. 3).

$\mathrm{b}$ Maximum wet diameter considered in this study (Table 1).

c Prediction of the Snider et al. (2003) model. The particle consists of a water-insoluble core surrounded by a $\mathrm{H}_{2} \mathrm{O} / \mathrm{Na}_{2} \mathrm{SO}_{4}$ solution. Temperature $=283.15 \mathrm{~K}$ and pressure $=900 \mathrm{hPa}$. Water activity corresponding to $\mathrm{Na}_{2} \mathrm{SO}_{4}$ weight percents larger than $40 \%$ are based on extrapolation of the 0 to $40 \% \mathrm{Na}_{2} \mathrm{SO}_{4}$ weight percent parameterization of Tang and Munkelwitz (1994).

\subsection{Particle sizing measurement error}

Strapp et al. (1992) showed that particle residence time inside the PCASP is $\sim 0.2 \mathrm{~s}$ and their model calculation, plus their flight data, indicated that submicron particles reside sufficiently long within the heated sampling section of the PCASP to evaporate to a diameter consistent with relative humidity less than $40 \%$ prior to the transit event. We repeated those calculations using the model of Snider et al. (2003) initialized with estimates of the hygroscopic mass fraction $\left(\varepsilon_{m}=0.8\right)$ and the chemical identity of the hygroscopic material. The latter assumption was guided by aerosol particle chemical composition measurements performed by other investigators. For wind speeds less than $10 \mathrm{~m} / \mathrm{s}$, for dry particle diameters smaller than $0.6 \mu \mathrm{m}$ and for summertime conditions, these analyses suggest that the materials ammonium bisulfate and sodium sulfate (McInnes et al., 1994; Quinn et al., 2000; Shinozuka et al., 2004), and water insoluble organic carbon and water soluble organic carbon (O'Dowd et al., 2004), dominate the composition of marine particles. Because the two sulfur containing materials have similar hygroscopic properties (Tang, 1996), and the hygroscopic properties of the water soluble organic carbon is not known with comparable accuracy, one of the two (sodium sulfate) was chosen as a surrogate hygroscopic material. Our model predicts the refractive index, density and water activity of a solution assumed to surround a water-insoluble core. The calculations presented in Table 2 demonstrate the following: 1) the $0.2 \mathrm{~s}$ particle residence time is sufficient for evaporation from one state $(\mathrm{RH}=96 \%)$ to the state assumed for detection within the PCASP $(\mathrm{RH}=40 \%)$ (This calculation employs a water vapor accommodation coefficient equal to 0.003 ; larger values of the coefficient result in shorter times for evaporation and vice versa); 2) water makes a substantial contribution to the size of the particle at $\mathrm{RH}=40 \%$; and 3) the refractive index of the particle at $\mathrm{RH}=40 \%$ is substantially different from that used to calibrate the PCASP.

Similar to the consideration given to equilibrium attainment inside the PCASP it is also necessary to consider equilibration between the ambient RH and the hydrated particles. This issue was examined by Feingold and Morely (2003) who modeled a parcel moving downward through the base of a warm stratus cloud. They showed that hydrated particles can be larger than the equilibrium (Köhler) prediction and that this disequilibrium persists to $50 \mathrm{~m}$ below the thermodynamic cloud base. Since all of our measurements were made at least $50 \mathrm{~m}$ below the thermodynamic cloud base we discount the significance of this disequilibrium between ambient RH and hydrated particle size.

We now present growth factor biases resulting from uncertainty in both particle refractive index and phase description. These are shown to lead to departures between the sphereequivalent dry diameter $\left(D_{\mathrm{dry}}\right)$, or the sphere-equivalent wet diameter $\left(D_{\text {wet }}\right)$, and the optically-detected particle diameter $D_{\text {OPC }}$. For particles sized in the F300, and of diameter smaller than the maximum of interest to this study ( $D=0.84 \mu \mathrm{m}$, Table 1 ), we use Rayleigh theory to account for the effect of different refractive indexes. Calculations presented by Baumgardner et al., 1992 (their Fig. 7) validate this approximation. For particles sized by the PCASP the Mie scattering intensity-to-diameter relationship deviates substantially from the Rayleigh prediction. The effect of the anticipated refractive index shift, from $n=1.59$ to $n=1.41$ 
Table 3. Growth factor bias due to sizing bias in the OPCs.

\begin{tabular}{|c|c|c|c|c|c|c|c|}
\hline & & PCASF & & & 00 & & \\
\hline $\begin{array}{l}\text { Assumption made } \\
\text { about particle } \\
\text { detected by PCASP }\end{array}$ & $\begin{array}{l}D_{\text {dry }} \\
\mathrm{nm}\end{array}$ & $\begin{array}{l}D_{40} \\
\mathrm{~nm}\end{array}$ & $\begin{array}{l}D_{\mathrm{OPC}} \\
\mathrm{nm}\end{array}$ & $\begin{array}{l}D_{\text {wet }} \\
\mathrm{nm}\end{array}$ & $\begin{array}{l}D_{\mathrm{OPC}} \\
\mathrm{nm}\end{array}$ & $G F_{\mathrm{OPC}}$ & $\left(G F_{\mathrm{OPC}}-G F\right) / G F$ \\
\hline $\begin{array}{l}\text { Spherical } \\
\mathrm{Na}_{2} \mathrm{SO}_{4} \\
\varepsilon_{m}=0.8, \rho_{\text {insoluble }}=1200 \mathrm{~kg} / \mathrm{m}^{3} \\
\text { Wet, } \mathrm{RH}=40 \%\end{array}$ & 450 & $558^{\mathrm{a}}$ & $420^{\mathrm{b}}$ & 738 & $770^{\mathrm{d}}$ & 1.83 & 0.12 \\
\hline $\begin{array}{l}\text { Spherical } \\
\mathrm{Na}_{2} \mathrm{SO}_{4} \\
\varepsilon_{m}=1.0 \\
\text { Wet } \mathrm{RH}=40 \%\end{array}$ & 450 & $603^{\mathrm{a}}$ & $452^{\mathrm{b}}$ & 738 & $770^{\mathrm{d}}$ & 1.70 & 0.04 \\
\hline $\begin{array}{l}\text { Spherical } \\
\mathrm{Na}_{2} \mathrm{SO}_{4} \\
\varepsilon_{m}=1.0 \\
\text { Dry }\end{array}$ & 450 & $\mathrm{NA}^{\mathrm{e}}$ & $338^{\mathrm{b}}$ & 738 & $770^{\mathrm{d}}$ & 2.27 & 0.38 \\
\hline $\begin{array}{l}\text { Cubical } \\
\mathrm{NaCl} \\
\varepsilon_{m}=1.0 \\
\text { Dry }\end{array}$ & 450 & $\mathrm{NA}^{\mathrm{e}}$ & $414^{\mathrm{c}}$ & 738 & $770^{d}$ & 1.86 & 0.13 \\
\hline
\end{tabular}

In this table $D_{\text {dry }}$ and $D_{\text {wet }}$ are assumed sphere-equivalent diameters related by $G F=D_{\text {wet }} / D_{\text {dry }}$ where $G F$ and RH are taken as the average values in Table $4(G F=1.64, \mathrm{RH}=89 \%) ; D_{\text {dry }}=450 \mathrm{~nm} ; D_{\text {wet }}=738 \mathrm{~nm} ; D_{40}$ is the sphere equivalent diameter at RH=40\% predicted by the Snider et al. (2003) model; $D_{\mathrm{OPC}}$ is the optical diameter detected by either the PCASP or F300; refractive indexes used for the F300 $D_{\mathrm{OPC}}$ calculation are $n=1.38$ (sodium sulfate solution at $\mathrm{RH}=89 \%$ ) and $n=1.33$ (pure water).

a Sphere equivalent diameters at $\mathrm{RH}=40 \%$ predicted by the Snider et al. (2003) model initialized with the Tang and Munkelwitz (1994) water activity parameterization. Water activity corresponding to $\mathrm{Na}_{2} \mathrm{SO}_{4}$ weight percents larger than $40 \%$ are based on extrapolation of the 0 to $40 \% \mathrm{Na}_{2} \mathrm{SO}_{4}$ weight percent parameterization of Tang and Munkelwitz (1994).

b Derived by multiplying an optical-to-sphere-equivalent diameter ratio $(0.75)$ times the values shown in the PCASP column labeled " $D_{40}$ ". The multiplier is based on measured sizes for dioctyl sebacate particles $(n=1.45)$ performed by Stolzenburg et al. (1998) (their Fig. 4).

${ }^{\mathrm{c}}$ Based on measurements performed by Liu et al. (1992) who challenged a PCASP with $0.28 \mu \mathrm{m}$ cubical NaCl particles (their Fig. 6).

$\mathrm{d}$ This calculation assumes Rayleigh scattering theory is applicable and is derived as $D_{\mathrm{OPC}}=D_{\mathrm{wet}} \cdot\left[\left(\frac{n_{1}^{2}-1}{n_{1}^{2}+2}\right)^{2} /\left(\frac{n_{2}^{2}-1}{n_{2}^{2}+2}\right)^{2}\right]^{1 / 6}$.

where $n_{1}$ is the index of refraction of the solution at RH=89\% predicted by the Snider et al. (2003) model $\left(n_{1}=1.38\right)$ and $n_{2}$ is the index of pure water $\left(n_{2}=1.33\right)$.

e NA=not applicable.

(Table 2), is quantified using an optical-to-sphere-equivalent diameter ratio which we estimate to be 0.75 based on measurements reported by Stolzenburg et al. (1998).

Our analysis of the $G F$ bias is contingent on a base case $G F$ state - derived with averaged measurements we discuss in Sect. $3.3(G F=1.64$ and $\mathrm{RH}=89 \%)-$ and on a modelderived property corresponding to this state $\left(\varepsilon_{m}=0.8\right.$, assuming sodium sulfate is the hygroscopic material and assuming the density of the non-hygroscopic material is $1200 \mathrm{~kg} / \mathrm{m}^{3}$ ). Table 3 presents perturbations about the base case state. First we consider a particle that does not effloresce in the PCASP.
At $\mathrm{RH}=40 \%$ our model predicts that a $\varepsilon_{m}=0.8$ sodium sulfate particle is $24 \%$ larger than its dry size; in the case of a $\varepsilon_{m}=1$ sodium sulfate particle this bias is $34 \%$. The size detected by the PCASP, however, is closer to the sphere-equivalent dry diameter $\left(D_{\text {dry }}\right)$ because of the factor $(0.75)$ we use to convert from the sphere-equivalent to optical diameter. The combined effects of metastable solution and refractive index are given in the first and second rows of Table 3 under the PCASP heading "DOPC."

In the preceding paragraph we assumed that the particle retains liquid water when detected by the PCASP. 
Alternatively, the solution can effloresce and in this scenario the sphere equivalent dry diameter of the resulting particle, likely aspherical, will be underestimated by approximately $8 \%$. This bias comes from measurements of Liu et al. (1992) who challenged a PCASP with $0.28 \mu \mathrm{m}$ cubical sodium chloride particles (Liu et al., 1992, their Fig. 6) and is shown in the final row of Table 3 under the PCASP heading " $D_{\text {OPC }}$ ".

Particles sized by the F300 are not pure water droplets; i.e., they contain solutes. For a droplet composed of water and sodium sulfate, and for the base case scenario the modelpredicted refractive index is 1.38 . This leads to an overestimation of the sphere-equivalent diameter by $\sim 4 \%$, according to Rayleigh theory, when we apply a refractive index of 1.33 to the below-cloud F300 measurements (Sect. 2.3). This result is presented in Table 3 under the F300 heading " $D_{\text {OPC }}$ ". In the penultimate column of Table 3 we report growth factors corresponding to the $D_{\mathrm{OPC}}$ values presented for the PCASP and F300 and use these to calculate the $G F$ biases shown in the final column. The biases we report indicate that $0.04<\left(G F_{\mathrm{OPC}}-G F\right) / G F<0.38$.

These errors will be different if light-absorbing materials contribute to the composition of the particles or if the finite time response of the F300 detection electronics is accounted for. The former of these is discussed in the following paragraph, and the latter is evaluated in Sect. 3.4.

Our model does not take into account the optical effect of the water-insoluble particle core. Mie scattering theory calculations performed by Fenn and Oser (1965) demonstrate that if the refractive index of the core differs substantially from that of the shell material, and if the volume fraction of the former is larger than several percent, then significant shifts can occur in the scattering phase function, particularly in the forward directions detected by the F300. Hence, if the insoluble portions of the sampled particles are composed of light absorbing materials (e.g., hematite or light-absorbing carbonaceous materials) consideration of an additional bias is needed. We cannot rule out the possibility that a significant amount of water-insoluble and light-absorbing material was present in the studied particles, but this possibility is attenuated by carbon monoxide measurements made on board the C-130 and by an analysis of airmass trajectories. The carbon monoxide mixing ratios were consistent with those encountered in remote marine areas (Ian Faloona, private communication, 2006) and the trajectories did not reveal any evidence for North American pollution contaminating the boundary layer air sampled by the C-130 (Petters, 2004). The trajectory analyses were extended backward five days and indicate that the sampled air originated over the north-central Pacific Ocean; near $140^{\circ} \mathrm{W}$ and $48^{\circ} \mathrm{N}$. From this origin the air tracks southwest toward the state of Oregon, turning south 300 to $400 \mathrm{~km}$ west of the coastline, where it parallels the Oregon and California coastlines for $1700 \mathrm{~km}$ before arriving at the DYCOMS-II target area $\left(122^{\circ} \mathrm{W}\right.$ and $\left.31^{\circ} \mathrm{N}\right)$.

Although we made several assumptions in our error analysis, including the use of a model to estimate the refractive index and reliance on our averaged $G F$ measurements for characterizing the base case scenario, we believe that the error analysis sets conservative limits on the accuracy of the $G F$ values we report.

\section{Analysis}

\subsection{Hygroscopic growth factor}

In this section we describe how the PCASP and F300 size spectra are combined to derive a hygroscopic growth factor. Averaged spectral densities (Sect. 2.4) derived for the two OPCs were compared over a restricted diameter range; this was selected by identifying a section of the size spectrum with constant slope in a double-logarithmic presentation of spectral density versus particle diameter. Channels lying within the constant-slope sections are indicated by small blue and red rectangles in the left and right panels of Fig. 2. These results are for an above-cloud and a below-cloud flight segment from 10 July 2001 (RF01). PCASP and F300 channelto-diameter assignments used in Fig. 2, and for all other analyzed flight segments, are provided in Table 1.

The averaged PCASP spectral densities, restricted to the constant-slope section, were fitted to a power function of the form

$$
\left(\frac{d N}{d \log _{10} D_{d}}\right)_{P}=\alpha_{P} \cdot D_{d}^{-\beta} .
$$

Here $\alpha_{P}$ and $\beta$ are fit parameters and $D_{d}$ symbolizes the dry particle diameter. For the F300 data a single parameter, $\alpha_{F}$, was fitted with the "slope parameter" $(\beta)$ prescribed by the PCASP fit

$$
\left(\frac{d N}{d \log _{10} D_{w}}\right)_{F}=\alpha_{F} \cdot D_{w}^{-\beta} .
$$

Here $D_{w}$ is the wet particle diameter and the assumed constancy of $\beta$ implies that the hygroscopic response is controlled solely by the solute effect (negligible Kelvin effect), implying that the wet diameter is a multiple of the dry diameter. These assumptions are consistent with the work of Fitzgerald (1975) if it is recognized that we characterize the hygroscopic response of particles with $D_{d} \geq 0.3 \mu \mathrm{m}$ at $\mathrm{RH} \leq 96 \%$. As we will see, the above mentioned multiple can be interpreted as the hygroscopic growth factor.

Our derivation of the growth factor relies on the equivalence of single point values of the fitted PCASP and F300 spectral densities, both evaluated within their respective constant-slope diameter ranges (Table 1). This equivalence is stated mathematically as

$\alpha_{P} \cdot D_{d}^{-\beta}=\alpha_{F} \cdot D_{w}^{-\beta}$.

The derivation of the $G F$ also requires the replacement of the wet diameter in Eq. (7) with $G F \cdot D_{d}$, on the assumption that 

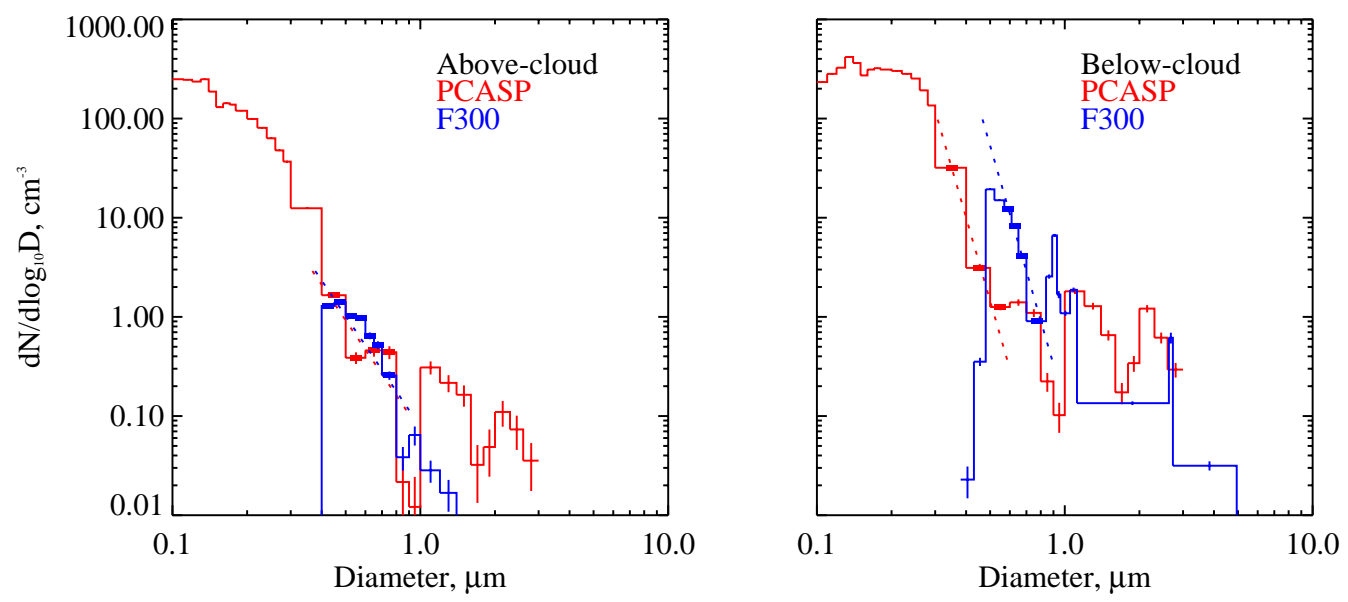

Fig. 2. Averaged size spectra reported by the F300 and PCASP on 10 July 2001 (RF01). Left plot is for the above-cloud flight segment (11:44 to 12:15 UTC), the right plot is for one of four RF01 below-cloud segments (13:00 to 13:30 UTC). PCASP and F300 channels falling in the constant-slope sections are indicated by red (PCASP) and blue (F300) rectangles. Fits of these data are shown as dashed red and blue lines. The Poisson error limits (Eq. 4) extend above and below the averaged spectral densities.
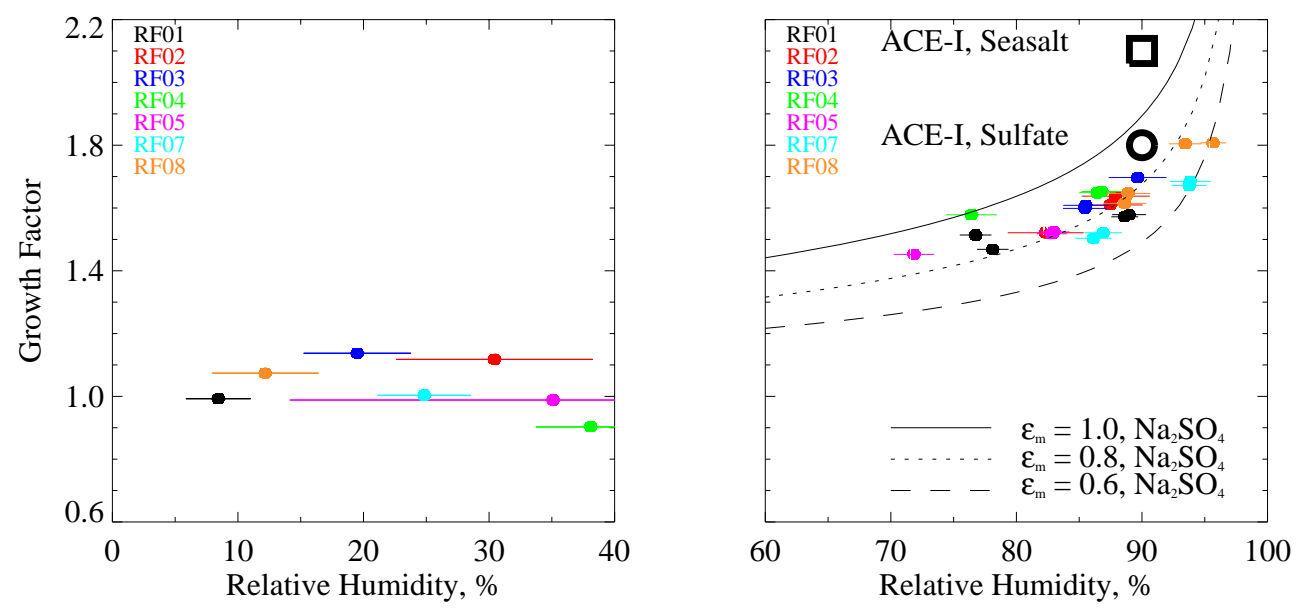

Fig. 3. Hygroscopic growth factor $(G F)$ versus ambient RH for above-cloud (left plot) and below-cloud (right plot) flight segments. The $G F$ and segment-averaged RH are indicated by a filled circle; horizontal lines extend from the averaged RH minus one standard deviation to the averaged RH plus one standard deviation. The right panel shows model predicted $G F$ curves for three hygroscopic mass fractions, a solute (sodium sulfate) and a non-hygroscopic material density $\left(1200 \mathrm{~kg} / \mathrm{m}^{3}\right)$. The metastable branch of the growth curves is shown below the deliquescence RH of sodium sulfate (84\% Tang and Munkelwitz, 1994). Also presented (open circle and square) are HTDMA GF averages for sulfate- and seasalt-dominant particles observed in an unpolluted ACE-1 airmass (Berg et al., 1998).

the $G F$ is a constant. With this assumption, which we discuss below, the hygroscopic growth factor is

$G F=\left(\alpha_{F} / \alpha_{P}\right)^{(1 / \beta)}$.

Derived in this way, the $G F$ represents the particle diameter shift needed to reconcile the dried PCASP spectrum with the humidified F300 spectrum.

The curve fitting discussed in the previous two paragraphs was conducted using a procedure known as "curvefit" (IDL, Research Systems Incorporated). Statistical weights passed to the procedure were evaluated as $1 / \sigma_{i}^{2}$ (Eq. 4). The derived $G F$ values correspond to a range of dry particle diameter extending from 0.4 to $0.8 \mu \mathrm{m}$ and from 0.3 to $0.6 \mu \mathrm{m}$ in analyses of the above- and below-cloud flight segments, respectively (Table 1). As we already discussed, these dry sizes are larger than that typically monitored by an HTDMA.

Equation (8) requires the substitution $D_{w}=G F \cdot D_{d}$, which for constant $G F$ implies that the same $\beta$ can be used to fit the PCASP and F300 spectra. Our approach is therefore contingent on $G F$ being constant over the diameter range that specifies the constant-slope section. This assumption would be violated if either the Kelvin effect or chemical composition varied strongly with dry particle diameter. Using our base case model (Sect. 2.5) we evaluated the partial derivative $\partial G F / \partial D_{d}$ and concluded from its very small magnitude that 
the size-dependent Kelvin effect is of no consequence for the range of particle diameters of interest to this work. We also note the relatively narrow range of dry diameter used in the $G F$ derivation, and in recognition of this, we discount the possibility of bias stemming from the constant composition assumption. Finally, we note that our hygroscopic growth factors should be comparable to that derived from instruments which report the $G F$ as the ratio of a humidified and dried particle diameter, e.g., an HTDMA.

In contrast to the HTDMA technique, our approach cannot distinguish between an aerosol that exhibits the same $G F$ for all particles of a prescribed size versus the situation of particles classifying (via HTDMA) in differing hygroscopic modes. These two scenarios are termed internal and external aerosol mixing states, respectively. For particles with a dry diameter $0.15 \mu \mathrm{m}$, observed in an unpolluted marine environment, two different particle types are detected by an HTDMA (Berg et al., 1998): 1) sulfate-dominant particles, having a growth factor of approximately 1.8 at $\mathrm{RH}=90 \%$, and 2) seasalt-dominant particles, having a growth factor of approximately 2.1 at $\mathrm{RH}=90 \%$. When the horizontal wind speed exceeds $10 \mathrm{~m} / \mathrm{s}$ the seasalt-dominant particle abundance can rival the sulfate-dominant particles (Nilsson et al., 2001). Because of these differing hygroscopic behaviors we expect to see a splitting of the F300 size spectrum at diameters slightly larger than the upper-limit size used in our analysis $(0.84 \mu \mathrm{m}$, Table 1$)$. Although the $0.9 \mu \mathrm{m}$ maximum seen in the right panel of Fig. 2, and in the other twentythree below-cloud F300 size spectra, may be indicative of the anticipated seasalt-dominant particles this is contradicted by three observations: 1) The particles sized by the F300 at $0.9 \mu \mathrm{m}$ could also be $G F=1.4$ particles originating from the local maximum in the PCASP spectrum seen at $0.65 \mu \mathrm{m}$ (Fig. 2, right panel). 2) The finite time response of the F300 electronics combined with the presence of the coarse aerosol mode centered at $\sim 1.5 \mu \mathrm{m}$ (wet diameter) leads to an enhancement of F300 spectral density at $\sim 0.9 \mu \mathrm{m}$. This prediction is based on the response matrix presented by Baumgardner et al. (1992) which we discuss in more detail in Sect. 3.4. 3 ) For the F300, and for $n=1.33$ and $n=1.59$, the two scattering intensity versus particle diameter relationships cross at $0.95 \mu \mathrm{m}$ where the $n=1.33$ relationship is about twice as steep as the $n=1.59$ relationship (Table 1). This crossing is also evident in Baumgardner et al. (1992). Our analysis of the effects of the finite time response of the F300 and of the narrowing of the channels that occurs when applying the $n=1.33$ sizing to data collected using $n=1.59$ sizing (results not shown), lead us to conclude that the spectral density maximum at $\sim 0.9 \mu \mathrm{m}$ may be artificial. A consequence is that we cannot attribute the $0.9 \mu \mathrm{m}$ maximum to the presence of seasalt-dominant particles. This conclusion applies to the twenty four below-cloud F300 spectra - the seven above-cloud F300 spectra do not exhibit a pronounced local maximum at $\sim 0.9 \mu \mathrm{m}$ (Fig. 2, left panel).

\subsection{Above-cloud $G F$ measurements}

Values of $G F$ for the seven above-cloud segments (one for each flight) are plotted in the left panel of Fig. 3. We expect these $G F$ to be close to unity because the ambient relative humidity $(\leq 36 \%)$ is not large enough for chemically-bound water to make a substantial contribution to the size of the particles detected by the F300. This is indeed the case with all of the above-cloud $G F$ values plotting within $\pm 17 \%$ of $G F=1$. The averaged $G F$ value is $1.06 \pm 0.09$ ( 7 above-cloud segments).

In addition to deriving the $G F$ for the seven above-cloud segments, the concentration of particles sizing within the constant-slope section was also evaluated. For each of the above-cloud segments the size-integrated concentration, corresponding to the channels footnoted with " $\mathrm{a}$ " in Table 1, was derived. The relative difference between the PCASP and F300 size-integrated concentration was computed. The average relative concentration difference is $-22 \pm 25 \%$ ( 7 above-cloud segments). Overall we conclude that segmentaveraged concentrations are in error by no more than 50\%, which is larger than our estimate of the relative bias associated with $G F$ (Sect. 2.5). Smaller relative bias associated with the $G F$ is a consequence of the fact that it is formulated as a ratio of quantities derived from measurements acquired by the F300 and PCASP (Eq. 8).

Inconsistencies between the F300 and PCASP size spectra are evident at diameters outside of the constant-slope section. For example, the two smallest diameter F300 channels (between 0.3 and $0.4 \mu \mathrm{m}, n=1.59$ sizing) have spectral densities four orders of magnitude smaller than that reported by the PCASP. Such values, corresponding to just a few transit events, are too small to plot in the left panel of Fig. 2. A likely reason for this undercounting is that the "trigger threshold" was set too high, prohibiting efficient particle counting. At diameters larger than $1 \mu \mathrm{m}$ an additional discrepancy is seen in the comparison of the F300 and PCASP size spectra. For example, the spectral density mismatch seen between 1 and $2 \mu \mathrm{m}$ is a factor of 20 with the PCASP again larger than the F300. The absence of overlapping Poisson error limits at these and larger diameters precludes attributing this discrepancy to the relatively small number of particles sampled (i.e., to Poissonian sampling error). The spectral density mismatch is decreased by our accounting of the finite time response of the F300 electronics (Sect. 3.4), but even after applying that correction the PCASP and F300 spectral densities at $\mathrm{D}>1 \mu \mathrm{m}$ can differ by as much as a factor of five (results not shown). We do not have an explanation for this disparity and it remains unclear which OPC is biased in this size range. 
Table 4. $\boldsymbol{G} \boldsymbol{F}$ and $\varepsilon_{m}$ values near $\mathrm{RH}=90 \%(87<\mathrm{RH}<93)$ evaluated without, and with, the response matrix correction of the F300 size spectrum.

\begin{tabular}{llllllll}
\hline Flight & $\begin{array}{l}\text { Time Interval, } \\
\text { UTC }\end{array}$ & $G F_{o}^{\mathrm{a}}$ & $\begin{array}{l}\mathrm{RH}, \\
\%\end{array}$ & $\begin{array}{l}G F \\
\text { without }\end{array}$ & $\begin{array}{l}\varepsilon_{m}^{\mathrm{b}} \\
\text { without }\end{array}$ & $\begin{array}{l}G F \\
\text { with }\end{array}$ & $\begin{array}{l}\varepsilon_{m}^{\mathrm{b}} \\
\text { with }\end{array}$ \\
\hline RF01 & $09: 28-09: 58$ & 1.84 & 90 & 1.6 & 0.75 & 1.8 & 0.93 \\
RF01 & $10: 00-10: 30$ & 1.85 & 89 & 1.6 & 0.75 & 1.8 & 0.94 \\
RF02 & $10: 00-10: 30$ & 1.81 & 88 & 1.6 & 0.84 & 1.8 & 1.02 \\
RF02 & $10: 33-11: 03$ & 1.80 & 88 & 1.6 & 0.82 & 1.8 & 1.01 \\
RF03 & $09: 30-10: 00$ & 1.88 & 90 & 1.7 & 0.86 & 1.9 & 1.02 \\
RF04 & $09: 48-10: 28$ & 1.78 & 87 & 1.6 & 0.87 & 1.8 & 1.02 \\
RF07 & $13: 06-13: 36$ & 1.78 & 87 & 1.5 & 0.73 & 1.7 & 0.90 \\
RF08 & $23: 25-23: 55$ & 1.85 & 89 & 1.6 & 0.81 & 1.8 & 0.96 \\
RF08 & $23: 57-00: 27$ & 2.12 & 93 & 1.8 & 0.75 & 1.9 & 0.86 \\
RF08 & $01: 39-02: 09$ & 1.84 & 89 & 1.6 & 0.78 & 1.8 & 0.94 \\
& Averages & & 89 & 1.64 & 0.80 & 1.81 & 0.98 \\
\hline
\end{tabular}

${ }^{\text {a }} G F_{O}$ is a reference growth factor evaluated from RH using the model of Snider et al. (2003) assuming the hygroscopic material is sodium sulfate, $\varepsilon_{m}=1$ and $283.15 \mathrm{~K}$.

${ }^{\mathrm{b}}$ Hygroscopic mass fraction evaluated as $\varepsilon_{m}=\left(\left(\frac{G F_{o}^{3}-1}{G F^{3}-1}-1\right) \cdot \frac{\rho_{i n}}{\rho_{s}}+1\right)^{-1}$ where $G F$ is the measured growth factor, $\rho_{i n}$ is the density of the non-hygroscopic material $\left(1200 \mathrm{~kg} / \mathrm{m}^{3}\right.$ is assumed) and $\rho_{s}$ is the density of sodium sulfate $\left(2680 \mathrm{~kg} / \mathrm{m}^{3}\right)$.

\subsection{Below-cloud $G F$ measurements}

Values of $G F$ derived for the twenty four below-cloud flight segments are presented in the right panel of Fig. 3. Also illustrated are model-predicted growth factors based on the following assumptions: 1) the hygroscopic material is sodium sulfate, 2) $\varepsilon_{m}=0.6,0.8$ or 1.0 , and 3) the non-hygroscopic material density is $1200 \mathrm{~kg} / \mathrm{m}^{3}$. For two flights (RF02 and RF03), and for three of four measurements from RF08, the slope of the $G F$ versus RH relationship is consistent with model prediction. Results from RF04 and RF07 suggest a shallower slope. It is unclear if this behavior is imposed by the measurement technique or if it reflects an actual property of the DYCOMS-II aerosol.

Also illustrated are HTDMA $G F$ averages reported by Berg et al. (1998) for ship-based measurements made within an unpolluted marine airmass sampled south of Tasmania during the first Aerosol Characterization Experiment (ACE1). The ACE-1 data is for particles of dry diameter $0.15 \mu \mathrm{m}$ and is shown for reported $G F$ modes corresponding to sulfate-dominant and seasalt-dominant particles. For our measurements corresponding to segment-averaged RHs between 87 and $93 \%$ - i.e. for a midpoint RH of $90 \%$ - the averaged $G F$ is $9 \%$ smaller than the ACE-1 GF value for sulfate-dominant particles. This subset of our data set is presented in Table 4. In the next section we demonstrate that part of the disparity between the ACE-I and DYCOMS-II data sets can be attributed to the finite time response of the F300 electronics.

\subsection{Time response of the F300}

For an assumed particle size and refractive index, the peak scattered light intensity detected by the F300 depends on the duration of the transit event and thus on the airspeed of the $\mathrm{C}$ 130 (Baumgardner et al., 1992). Using measurements of the time response of the F300 photodetector amplifiers, Baumgardner et al. derived relative light scattering intensities at a small $(10 \mathrm{~m} / \mathrm{s})$ and large airspeed $(200 \mathrm{~m} / \mathrm{s})$. By repeating this calculation for all channels of the F300, a response matrix was developed and a correction method was proposed. The method compensates for how the measured size spectrum is biased toward smaller particle size because of the finite time response of the amplifiers. The effect of the correction is shown in Table 4 for measurements made at RH values between 87 and 93\% (10 below-cloud segments); on average the relative $G F$ increase is $9 \%$. Since this correction is for a $200 \mathrm{~m} / \mathrm{s}$ airspeed, a factor of 1.8 larger that of the C-130, it is expected to produce an upper-limit growth factor shift. From this we conclude that the $9 \%$ discrepancy between the DYCOMS-II and ACE-I measurements of $G F$, both made at RH 90\% (Sect. 3.3), cannot be completely reconciled by the airspeed-dependent undersizing that occurs in the F300; however, a F300 response matrix corresponding to $110 \mathrm{~m} / \mathrm{s}$ is required to be certain about this. Not having that matrix we predict that the correction will be substantially smaller than that derived using the $200 \mathrm{~m} / \mathrm{s}$ matrix. 


\section{Discussion}

The $G F$ values we report for the RH interval 87 to $93 \%$ range from 1.5 to 1.8 (Table 4, fifth column). The right panel of Fig. 3 demonstrates that these growth factors are smaller than measurements made in a marine southern hemisphere airmass thought well-removed from the influence of continental aerosols (Berg et al., 1998). Growth factor values from the comparison study (ACE-1) also demonstrate the aerosols sampled from the atmosphere, dried, and mobility selected at $0.15 \mu \mathrm{m}$ can exist as an external mixture of sulfate-dominant and seasalt-dominant particles. The comparison $G F$ values are $1.8 \pm 0.1$ and $2.1 \pm 0.1$ for growth modes attributed to sulfate- and seasalt-dominant particles, respectively ( $\mathrm{RH}=90 \%)$. These results come from HTDMA measurements conducted on board a ship.

Ship-based measurements conducted within the subtropical Atlantic (Swietlicki et al., 2000) and Arctic (Zhou et al., 2001) ocean basins are broadly consistent with the ACE-I averages discussed in the previous paragraph. These additional studies also show that the seasalt- to sulfate-dominant particle ratio is less than 0.1 when sampling at wind speeds less than $10 \mathrm{~m} / \mathrm{s}$. These ship-based data correspond to measurements made at $10 \mathrm{~m}$ above sea level (a.s.l.). For our data set, restricted to data collected at or above $95 \mathrm{~m}$ a.s.l., the segment-averaged wind speeds ranged between 5 and $12 \mathrm{~m} / \mathrm{s}$ and were usually $7 \mathrm{~m} / \mathrm{s}$. Since the DYCOMS-II wind speeds at $95 \mathrm{~m}$ a.s.l. were typically smaller than $10 \mathrm{~m} / \mathrm{s}$ we assert that the fraction of seasalt-dominant particles was less than 0.1 for particles sizing between the dry diameters 0.3 and $0.6 \mu \mathrm{m}$.

Since seasalt-dominant particles are thought to have made only a small contribution to the $G F$ values we document, and because the air we sampled did not appear to originate from North America (Sect. 2.5), we conclude that the most appropriate comparator for our result is the $G F$ reported for sulfate-dominant particles during ACE-1. Here we compare our result to ACE-1 and also consider upper and lower limit estimates by evoking the $G F$ bias discussed in Sect. 2.5. The comparison uses the average of ten measurements, corresponding to RH between 87 and $93 \%$, presented in the bottom row of Table 4.

First, we consider the upper-limit for our $G F$ measurements $\left(100 \cdot\left(G F_{\mathrm{OPC}}-G F\right) / G F=4 \%\right.$, Sect. 2.5). As is shown in the bottom row of Table 4 the averaged $G F_{\text {OPC }}$ is $1.64 ; 9 \%$ smaller than the ACE-1 result. Because the $+4 \%$ bias suggests that the derived $G F_{\mathrm{OPC}}$ is larger than the actual $G F$ we conclude that the hygroscopic behavior during DYCOMS-II may have been $13 \%$ smaller than that during ACE-I. In that case (i.e., the actual $G F=1.57$ ), assuming the hygroscopic material is sodium sulfate and the nonhygroscopic material density is $1200 \mathrm{~kg} / \mathrm{m}^{3}$, the hygroscopic mass fraction predicted by our model is $\varepsilon_{m} \sim 0.72$. Further, since we do not have a response matrix to account for the time response of the F300 when operated on the C-130 at

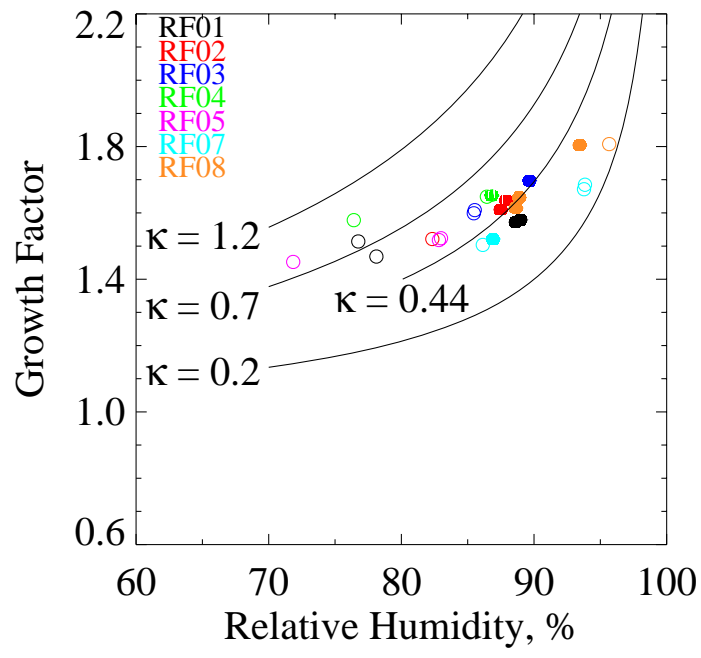

Fig. 4. Hygroscopic growth factor $(G F)$ versus segment-averaged ambient RH for below-cloud flight segments. The ten points with RH values between $87 \%$ and $93 \%$ are indicated by filled circles; for these the average value $\kappa=0.44$ is derived (Eq. 6 in Petters and Kreidenweis(2007) assuming $D_{d}=450 \mathrm{~nm}$ ) and the corresponding $G F$ versus RH relationship is plotted. The other measurements are shown with open circles. $G F$ versus $\mathrm{RH}$ relationships are also plotted for $\mathrm{NaCl}(\kappa=1.2), \mathrm{Na}_{2} \mathrm{SO}_{4}(\kappa=0.7)$ and for a moderately hygroscopic material $(\kappa=0.2)$ (Petters and Kreidenweis, 2007).

$110 \mathrm{~m} / \mathrm{s}$, and because we argue that the correction is substantially smaller than $9 \%$ (Sect. 3.4), we do not see justification in diminishing the $13 \%$ difference between ACE-I and DYCOMS-II to account for this compensating bias. As such, the $G F_{\mathrm{OPC}}=1.64$ appears to preclude the possibility that the 0.3 to $0.6 \mu \mathrm{m}$ dry particles had hygroscopicities equivalent to the ACE-1 seasalt-dominant particles $(G F=2.1)$.

The possibility that the DYCOMS-II growth factors were substantially less than expected for seasalt-dominant particles is contradicted by the work of Feingold and Morely (2003). Using lidar measurements of aerosol backscatter, PCASP measurements of aerosol size spectra, an assumed composition for the accumulation and coarse mode particles $\left(\mathrm{NaCl}, \varepsilon_{m}=1\right)$ and Mie scattering theory these authors compared two independent assessments of normalized aerosol backscatter. They concluded that the two were in reasonable agreement. This inference was based on the data from the flight segment used to construct the right panel of our Fig. 2. From our measurements of $G F=1.52$ ( $\mathrm{RH}=77 \%)$, and with the assumptions that the hygroscopic material is $\mathrm{NaCl}$ and the non-hygroscopic material density is $1200 \mathrm{~kg} / \mathrm{m}^{3}$, our model predicts $\varepsilon_{m}=0.55$. We reconcile this disparate result by noting that Feingold and Morely normalized their backscatter values to $\mathrm{RH}=85 \%$ which may have diminished the sensitivity of their successful closure to $\varepsilon_{m}$. Complete resolution this issue will require examination of C-130 lidar data from other DYCOMS-II flights and comparison of our technique to a method other than lidar. 
Next, we consider a lower limit for the average $G F$ we report. In this scenario ( $G F$ bias $=38 \%$, Sect. 2.5$)$ the averaged $G F_{\mathrm{OPC}}=1.64(\mathrm{RH}=89 \%)$ becomes $G F_{\mathrm{OPC}}=1.2$ and our model predicts $\varepsilon_{m} \sim 0.3$, assuming the hygroscopic material is sodium sulfate and the non-hygroscopic material density is $1200 \mathrm{~kg} / \mathrm{m}^{3}$.

The hygroscopic behavior we present in Table 4 can be used to interpret aerosol size spectra measurements as cloud condensation nuclei activation spectra. A disadvantage of this approach is that $G F$ is not sufficient for constraining both $\varepsilon_{m}$ and the chemical identity of the hygroscopic material. Petters and Kreidenweis (2007) and Rissler et al. (2006) propose the use of a single parameter $\kappa$ which encompasses both properties and which can be derived from either $G F$ or cloud condensation nuclei measurements. We note that $\kappa$ describes the relationship between $\mathrm{RH}$ and $G F$ as well as the relationship between critical supersaturation and particle dry diameter. Figure 4 shows lines of constant $\kappa$ with our growth factor data. A value $\kappa=0.44$ is the average for the ten data points satisfying condition $87 \%<\mathrm{RH}<93 \%$ (filled circles). We note that this average is smaller than that of sodium sulfate $(\kappa \sim 0.7)$ and inorganic compounds in general (cf. Table 1 in Petters and Kreidenweis 2007). Also, for a mixed particle the $\kappa$ can be formulated as the volumefraction-weighted sum of $\kappa$ for the components. Undissolved species are non-hygroscopic and for these $\kappa=0$. Two plausible internal mixing scenarios for $\kappa=0.44$ are $63 \%$ inorganic material $(\kappa=0.7)$ with $37 \%$ insoluble material, or $48 \%$ inorganic material $(\kappa=0.7)$ with $52 \%$ moderately hygroscopic material $(\kappa=0.2)$.

\section{Summary}

We report a technique that derives the aerosol hygroscopic growth factor from data acquired by two concurrently operated airborne optical particle counters. The advantages of our approach are that it is based on instruments that are common to aerosol physics aircraft operated in North America and Europe and that it is now available for evaluation of the hygroscopic response of dry particles sizing between 0.3 and $0.6 \mu \mathrm{m}$. Results from the DYCOMS-II campaign suggest that a significant fraction of the particulate mass, up to $70 \%$ depending on the degree of measurement bias, is nonhygroscopic.

Although the hygroscopic mass fractions we derive are plausible for the DYCOMS-II study region, for example Quinn et al. (2000) show that submicron residual mass fractions (presumably non-hygroscopic or weakly hygroscopic material) range between 0.29 and 0.45 over the northeastern Pacific Ocean, we also report on measurement error (bias) in our $G F$ values. Bias results from our limited understanding of the extent of particle drying that occurs prior to detection inside PCASP, from uncertainties stemming from the related problem of particle shape inside the PCASP, and from uncer- tain particle refractive index during detection in both optical particle counters. The range of $G F$ bias is +4 to $+38 \%$, and is thus possibly a factor of ten larger than that for an HTDMA (Swietlicki et al., 2000). Bias associated with our technique could be minimized by measuring the relative humidity of aerosol entering the scattering volume of the PCASP, to see if this is consistent with previous estimates and for validating the $G F$ bias we report. The latter depends on the PCASP relative humidity value we adopted from Strapp et al. (1992). Examination of the undersizing which occurs at the airspeed of the $\mathrm{C}-130$ and a comparison of the $\mathrm{F} 300$ response matrix of Baumgardner et al. (1992) to a response matrix derived using laboratory test aerosol (Jonsson et al., 1995) could also lead to substantial refinement. Such efforts are needed to advance this new $G F$ technique and should help improve quantitative understanding of the hygroscopic behavior of particles with dry diameter larger than $0.3 \mu \mathrm{m}$.

Acknowledgements. We thank C. Twohy and T. Eidhammer for critiquing early versions of the manuscript. We thank D. Baumgardner helping us understand the F300 and Y. Cai for the calculations he generously provided. This work was supported by NSF grant ATM-0103951. Any opinions, findings, and conclusions are those of the authors and do not necessarily reflect the views of the National Science Foundation.

Edited by: G. Feingold

\section{References}

Baumgardner, D., Dye, J. E., Gandrud, G. B., and Knollenberg, R. G.: Interpretation of measurements made by the forward scattering spectrometer probe (FSSP-300) during the airborne arctic stratospheric expedition, J. Geophys. Res., 97, D8, 8035-8046, 1992.

Baumgardner, D. and Clarke, A.: Changes in aerosol properties with relative humidity in the remote southern hemisphere marine boundary layer, J. Geophys. Res, 103, 16 525-16 534, 1998.

Berg, O. H., Swietlicki, E., and Krejci, R.: Hygroscopic growth of aerosol particles in the marine boundary layer over the $\mathrm{Pa}$ cific and Southern Oceans during the First Aerosol Characterization Experiment (ACE 1), J. Geophys. Res., 103, D13, 16 535$16545,1998$.

Boucher, O. and Anderson, T. L.: General circulation model assessment of the sensitivity of direct climate forcing by anthropogenic sulfate aerosols to aerosol size and chemistry, J. Geophys. Res., 100, D12, 26 117-26 134, 1995.

Brechtel, F. J. and Kreidenweis, S. M.: Predicting particle critical supersaturation from hygroscopic growth measurements in the humidified TDMA. Part I: Theory and sensitivity studies, J. Atmos. Sci., 57, 12, 1854-1871, 2000.

Collins, D. R., Jonsson, H. H., Seinfeld, J. H., Flagan, R. C., Gasso, S., Hegg, D. A., Russell, P. B., Schmid, B., Livingston, J. M., Ostrom, E., Noone, K. J., Russell, L. M., and Putaud, J. P.: In situ aerosol-size distributions and clear-column radiative closure during ACE-2, Tellus B, 52, 498-525, 2000. 
Feingold, G. and Morley, B.: Aerosol hygroscopic properties as measured by lidar and comparisons with in situ measurements, J. Geophys. Res., 108, D11, 4327, doi:10.1029/2002JD002842, 2003.

Fenn, R. W. and Oser, H.: Scattering properties of concentric sootwater spheres for visible and infrared light, Appl. Optics, 4, 11, 1504-1509, 1965.

Fitzgerald, J. W.: Approximation formulas for the equilibrium size of an aerosol particle as a function of its dry size and composition and the ambient relative humidity, J. Appl. Meteorol., 14, 10441049, 1975.

Guibert, S., Snider, J. R., and Brenguier, J.-L.: Aerosol activation in marine stratocumulus clouds: 1 . Measurement validation for a closure study, J. Geophys. Res, 108, D15, D8628, doi:10.1029/2002JD002678, 2003.

Hegg, D. A., Covert, D. S., Crahan, K. K., Jonsson, H. H., and Liu, Y.: Measurements of aerosol size-resolved hygroscopicity at sub and supermicron sizes, Geophys. Res. Lett., 33, 21, L21808, doi:10.1029/2006GL026747, 2006.

Hitzenberger, R., Berner, A., Dusek, U., and Alabashi, R.: Humidity-dependent growth of size-segregated aerosol samples, Aerosol Sci. Technol., 27, 116-130, 1997.

Jonsson, H. H., Wilson, J. C., Brock, C. A., Knollenberg, R. G., Newton, R., Dye, J. E., Baumgardner, D., Borrmann, S., Ferry, G. V., Pueschel, R., Woods, D. C., and Pitts, M. C.: Performance of a focused cavity aerosol spectrometer for measurements in the stratosphere of particle-size in the 0.06-2.0- $\mu \mathrm{m}$-diameter range, J. Atmos. Ocean. Tech., 12, 115-129, 1995.

Kotchenruther, R. A. and Hobbs, P. V.: Humidification factors of aerosols from biomass burning in Brazil, J. Geophys. Res., 103, 32 081-32 089, 1998.

Kreidenweis, S. M., Koehler, K., DeMott, P. J., Prenni, A. J., Carrico, C., and Ervens, B.: Water activity and activation diameters from hygroscopicity data - Part I: Theory and application to inorganic salts, Atmos. Chem. Phys., 5, 1357-1370, 2005, http://www.atmos-chem-phys.net/5/1357/2005/

Liu, P. S. K., Leaitch, W. R., Strapp, J. W., and Wasey, M. A.: Response of particle measurement systems airborne ASASP and PCASP to $\mathrm{NaCl}$ and latex particles, Aerosol Sci. Technol., 16, 83-95, 1992.

Marcolli, C., Luo, B. P., and Peter, T.: Mixing of the organic aerosol fractions: Liquids as the thermodynamically stable phases, J. Phys. Chem. A., 108, 12, 2216-2224, 2004.

Martin, S. T.: Phase transitions of aqueous atmospheric particles, Chem. Rev., 100, 9, 3403-3453, 2000.

Massling, A., Stock, M., and Wiedensohler, A.: Diurnal, weekly, and seasonal variation of hygroscopic properties of submicrometer urban aerosol particles, Atmos. Environ., 39, 21, 3911-3922, 2005.

McFiggans, G., Artaxo, P., Baltensperger, U., Coe, H., Facchini, M. C., Feingold, G., Fuzzi, S., Gysel, M., Laaksonen, A., Lohmann, U., Mentel, T. F., Murphy, D. M., O’Dowd, C. D., Snider, J. R., and Weingartner, E.: The effect of physical and chemical aerosol properties on warm cloud droplet activation, Atmos. Chem. Phys., 6, 2593-2649, 2006, http://www.atmos-chem-phys.net/6/2593/2006/

McInnes, L. M., Covert, D. S., Quinn, P. K., and Germani, M. S.: Measurements of Chloride Depletion and Sulfur Enrichment in Individual Sea-Salt Particles Collected from the Remote Marine
Boundary-Layer, J. Geophys. Res., 99, D4, 8257-8268, 1994.

McMurry, P. H. and Stolzenburg, M. R.: On the sensitivity of particle-size to relative-humidity for Los-Angeles aerosols, Atmos. Environ., 23, 497-507, 1989.

Mertes, S., Lehmann, K., Nowak, A., Massling, A., and Wiedensohler, A.: Link between aerosol hygroscopic growth and droplet activation observed for hill-capped clouds at connected flow conditions during FEBUKO, Atmos. Environ, 39, 4247-4256, 2005.

Nilsson, E. D., Rannik, U., Swietlicki, E., Leck, C., Aalto, P. P., Zhou, J., and Norman, M.: Turbulent aerosol fluxes over the Arctic Ocean 2. Wind-driven sources from the sea, J. Geophys. Res., 106, D23, 32 139-32 154, 2001.

O’Dowd, C. D., Facchini, M. C., Cavalli, F., Ceburnis, D., Mircea, M., Decesari, S., Fuzzi, S., Yoon, Y. J., and Putaud, J.-P.: Biogenically driven organic contribution to marine aerosol, Nature, 431, 676-680, 2004.

Parsons, M. T., Knopf, D. A., and Bertram, A. K.: Deliquescence and crystallization of ammonium sulfate particles internally mixed with water-soluble organic compounds, J. Phys. Chem. A., 108, 52, 11 600-11 608, 2004.

Petters, M. D.: Cloud Condensation Nuclei: Measurement, Prediction and Effects on Remote Marine Stratocumulus Clouds, Ph.D. Dissertation, University of Wyoming, 156 pp., 2004.

Petters, M. D. and Kreidenweis, S. M.: A single parameter representation of hygroscopic growth and cloud condensation nucleus activity, Atmos. Chem. Phys., 7, 1961-1971, 2007, http://www.atmos-chem-phys.net/7/1961/2007/.

Petters, M. D., Snider, J. R., Stevens, B., Vali, G., Faloona, I., and Russell, L. M.: Accumulation mode aerosol, pockets of open cells, and particle nucleation in the remote subtropical Pacific marine boundary layer, J. Geophys. Res., 111, D2, D02206, doi:10.1029/2004JD005694, 2006.

Quinn, P. K., Bates, T. S., Miller, T. L., Coffman, D. J., Johnson, J. E., Harris, J. M., Ogren, J. A., Forbes, G., Anderson, T. L., Covert, D. S., and Rood, M. J.: Surface submicron aerosol chemical composition: What fraction is not sulfate?, J. Geophys. Res., 105, D5, 6785-6805, 2000.

Rissler, J., Vestin, A., Swietlicki, E., Fisch, G., Zhou, J., Artaxo, P., and Andreae, M. O.: Size distribution and hygroscopic properties of aerosol particles from dry-season biomass burning in Amazonia, Atmos. Chem. Phys., 6, 471-491, 2006, http://www.atmos-chem-phys.net/6/471/2006/.

Rood, M. J., Shaw, M. A., Larson, T. V., and Covert, D. S.: Ubiquitous nature of ambient metastable aerosol, Nature, 337, 6207, 537-539, 1989.

Santarpia, J. L., Li, R., and Collins, D. R.: Direct measurement of the hydration state of ambient aerosol populations, J. Geophys. Res., 109, D18209, doi:10.1029/2004JD004653, 2004.

Shinozuka, Y., Clarke, A. D., Howell, S. G., Kapustin, V. N., and Huebert, B. J.: Sea-salt vertical profiles over the Southern and tropical Pacific oceans: Microphysics, optical properties, spatial variability, and variations with wind speed, J. Geophys. Res., 109, D24, D24201, doi:10.1029/2004JD004975, 2004.

Snider, J. R., Guibert, S., Brenguier, J. L., and Putaud, J. P.: Aerosol activation in marine stratocumulus clouds: 2 . Köhler and parcel theory closure studies, J. Geophys. Res., 108, D15, 8629, doi:10.1029/2002JD002692, 2003.

Stevens, B., Lenshow, D. H., Vali, G., Gerber, H., Bandy, A., Blomquist, B., Brenguier, J.-L., Bretherton, C. S., Burnet, F., 
Campos, T., Chai, S., Faloona, I., Friesen, D., Haimov, S., Laursen, K., Lilly, D. K., Loehrer, S. M., Malinowski, S. P., Morely, B., Petters, M. D., Rogers, D. C., Russell, L. M., SavicJovcic, V., Snider, J. R., Straub, D., Szumowski, M., Takagi, H., Thorton, D. C., Tschudi, M., Twohy, C. H., Wetzel, M., and vanZanten, M. C.: Dynamics and Chemistry of Marine Stratocumulus-DYCOMS-II, Bull. Amer. Meteor. Soc., 83, 579593, 2003.

Stolzenburg, M., Kreisberg, N., and Hering, S.: Atmospheric size distributions measured by differential mobility optical particle size spectrometry, Aerosol Sci. Tech., 29, 402-418, 1998.

Strapp, J. W., Leaitch, W. R., and Liu, P. S. K.: Hydrated and dried aerosol-size-distribution measurements from Particle Measuring Systems FSSP-300 probe and deiced PCASP-100X probe, J. Atmos. Oceanic. Technol., 9, 548-555, 1992.

Svenningsson, B., Hansson, H. C., Wiedensohler, A., Noone, K., Ogren, J., Hallberg, A., and Colvile, R.: Hygroscopic Growth of Aerosol-Particles and its Influence on Nucleation Scavenging inCloud-Experimental Results from Kleiner-Feldberg, J. Atmos. Chem., 19, 129-152, 1994.

Svenningsson, B., Rissler, J., Swietlicki, E., Mircea, M., Bilde, M., Facchini, M. C., Decesari, S., Fuzzi, S., Zhou, J., Monster, J., and Rosenorn, T.: Hygroscopic growth and critical supersaturations for mixed aerosol particles of inorganic and organic compounds of atmospheric relevance, Atmos. Chem. Phys., 6, 1937-1952, 2006, http://www.atmos-chem-phys.net/6/1937/2006/.

Swietlicki, E., Zhou, J., Covert, D. S., Hämeri, K., Busch, B., Väkevä, M., Dusek, U., Berg, O. H., Wiedensohler, A., Aalto, P. P., Mäkelä, J., B. J. Martinsson, G. Papaspiropoulos, B. Mentes, F. Göran and F. Stratmann. Hygroscopic properties of aerosol particles in the north-eastern Atlantic during ACE-2, Tellus, 52B, 201-227, 2000.
Tang, I. N.: Chemical and size effects of hygroscopic aerosols on light scattering coefficients, J. Geophys. Res., 101, D14, 19245$19250,1996$.

Tang, I. N. and Munkelwitz, H. R.: Water activities, densities, and refractive-indexes of aqueous sulfates and sodium-nitrate droplets of atmospheric importance, J. Geophys. Res., 99, D9, 18 801-18 808, 1994.

Turšič, J., Podkrajšek, B., Grgić, I., Ctyroky, P., Berner, A., Dusek, U., and Hitzenberger, R.: Chemical composition and hygroscopic properties of size-segregated aerosol particles collected at the Adriatic coast of Slovenia, Chemosphere, 63, 1193-1202, 2006.

vanZanten, M. C., Stevens, B., Vali, G., and Lenshow, D. H.: Observations of drizzle in nocturnal marine stratocumulus, J. Atmos. Sci., 62, 88-106, 2005.

Weber, R. J., Clarke, A. D., Litchy, M., Kok, L. J. G., Schillawski, R. D., and McMurry, P. H.: Spurious aerosol measurements when sampling from aircraft in the vicinity of clouds, J. Geophys. Res., 103, 28 337-28 346, 1998.

Wulfmeyer, V. and Feingold, G.: On the relationship between relative humidity and particle backscattering coefficient in the marine boundary layer determined with differential absorption lidar, J. Geophys. Res., 105, D4, 4729-4741, 2000.

Young, H. D.: Statistical Treatment of Experimental Data, 172 pp., New York, McGraw-Hill, 1962.

Zhou, J., Swietlicki, E., Berg, O. H., Aalto, P. P., Hämeri, K., Nilsson, E. D., and Leck, C.: Hygroscopic properties of aerosol particles over the central Arctic Ocean during summer, J. Geophys. Res., 107, D20, 32 111-32 124, 2001. 